\title{
Dynamics of culling risk with disposal codes reported by Dairy Herd Improvement dairy herds
}

\author{
P. J. Pinedo, A. De Vries, ${ }^{1}$ and D. W. Webb \\ Department of Animal Sciences, University of Florida, Gainesville 32611
}

\begin{abstract}
The objective was to describe the dynamics of culling risk with disposal codes for Holstein dairy cows reported by herds enrolled in the Dairy Herd Improvement program. Dairy producers could report 1 of 9 possible disposal codes or forego reporting a code. After edits, $3,629,002$ lactation records were available for cows calving between 2001 and 2006 in 2,054 herds located in 38 states primarily east of the Mississippi river. The distribution of culled cows by disposal code was estimated by parity, days after calving, pregnancy status, cow-relative 305-d mature equivalent milk yield, herd-relative 305-d mature equivalent milk yield, and season. Of all herds, $57 \%$ reported all 8 different disposal codes excluding the codes dairy purposes and reason not reported. Hazard (risk) functions were calculated by parity, from 1 to 520 $\mathrm{d}$ since calving for open cows and from 1 to $280 \mathrm{~d}$ since conception for pregnant cows. Annualized live culling rate and death rate (reported code was death) were 25.1 and $6.6 \%$, respectively. The primary disposal code was died (20.6\% of all culling), followed by reproduction $(17.7 \%)$, injury/other $(14.3 \%)$, and low production and mastitis (both 12.1\%). The risk of culling with various disposal codes varied with stage of lactation. Died and reproduction were the most frequently reported codes for cows leaving the herd during early and late lactation, respectively. Early lactation was also a critical period for culling with the disposal codes injury/other and disease, and the risk increased with days after calving for the codes low production and reproduction. The risk of culling with the disposal code died showed the greatest seasonal pattern with increased risk of death in spring and summer. A negative association was found between annualized live culling and death rates within herds. Compared with open cows, pregnant cows had a lower risk of culling with all reported disposal codes. In
\end{abstract}

Received July 15, 2009.

Accepted January 25, 2010.

${ }^{1}$ Corresponding author: devries@ufl.edu addition, the risk of culling was lower in high-producing cows with all disposal codes. In conclusion, the risk for culling by disposal code varied by parity, stage of lactation, season, pregnancy status, and milk yield.

Key words: culling, death, risk

\section{INTRODUCTION}

Longevity, defined as the time from first calving until culling or censoring, is determined by voluntary and involuntary decisions at the farm level (Sewalem et al., 2008). In recent years, Holstein cows have shown a trend for lower survival rates (Hare et al., 2006; Miller et al., 2008). Today's high involuntary culling rates are a concern on dairy farms from both an animal wellbeing and an economic point of view (Weigel et al., 2003).

Culling is the departure of cows from the herd because of sale, slaughter, salvage, or death (Fetrow et al., 2006). Culling risks are affected by physiological processes, such as calving, lactation, energy balance, reproduction, and aging. A critical time for survival is the transition period, during which cows experience a series of rapidly changing physiological statuses and most of the metabolic diseases occur (Goff and Horst, 1997). The greatest risk of culling has been reported in early lactation and after $420 \mathrm{~d}$ post-calving (Fetrow et al., 2006), with culling rates by 60 DIM close to $8 \%$ (Dechow and Goodling, 2008). As expected, greater parity was also related to the greatest risk of culling (van Arendonk and Dijkhuizen, 1985; Thomsen et al., 2004; Miller et al., 2008).

Previous studies have investigated the frequencies of reported disposal codes for culling in dairy herds (Van Vleck and Norman, 1972; Milian-Suazo et al., 1988; Bascom and Young, 1998; Smith et al., 2000; Hadley et al., 2006). However, recent studies describing the dynamics and risk factors for culling with reported DHI disposal codes, considering parity, stage of lactation, pregnancy status, season, and herd characteristics, are missing. It is presumable that the reported risk of culling with various disposal codes depends on the time after calving and other concurrent conditions affecting individual cows. Such information would be useful 
because it provides insight into what dairy producers perceive as the major reason for cows leaving the herd and for future cash flow projections.

A strong association between reproductive performance and cow survival has been stated (Rajala-Schultz and Gröhn, 1999; Schneider et al., 2007). Cows that required more services per conception, had an interval between calving to first service greater than $90 \mathrm{~d}$, and had increased days open were at greater risk of being culled (Milian-Suazo et al., 1989; Sewalem et al., 2008). Nevertheless, the association of reproductive status and the risk of culling with the various disposal codes has not been quantified.

The objective of this observational study was to describe the dynamics of culling risk with reported DHI disposal codes by parity, stage of lactation, milk yield, reproductive status, herd milk yield, and herd size in larger ( $>100$ cows) Holstein dairy herds enrolled in the DHI program.

\section{MATERIALS AND METHODS}

\section{Study Population}

The study analyzed DHI lactation records from herds located in 38 states primarily east of the Mississippi river. A total of 14 million records of cows calving between January 2001 and December 2006 were available. Data were provided by Dairy Records Management Systems (Raleigh, NC) and consisted of calving date, parity, date of dry-off, 305-d mature equivalent (305ME) milk yield, herd code and state, breeding data, and reported disposal code and date. Only 1 disposal code per culled cow was reported. The following 10 disposal codes were reported: feet and legs, dairy purposes, low production, reproduction, injury/other, mastitis, disease, udder problems, died, and reason not reported (DRMS, 2004). The code reason not reported was entered by DHI. Culling was considered removal from the herd with any disposal code other than dairy purposes. Live culling included all disposal codes except died. Consequently, in the analysis of annualized culling rates, the disposal code died was considered separately.

\section{Data Edits}

The analyses were restricted to Holstein cows. Lactation records missing parity number or calving date or from herds with $<100$ milking cows (annual average) were removed from the data set. Dates of calving, conception, culling, and last known event were determined for each lactation record. Subsequent calving dates were obtained from the following lactation. Records that ended with the subsequent calving were considered completed. Records that ended in culling or that were censored were incomplete.

Cows were considered pregnant if their last reported pregnancy status was $\mathrm{P}$ (diagnosed pregnant) or E (estimated bred data, cow is assumed to be pregnant). Conception dates for completed records were calculated by adding the reported days to conception to the calving date starting the lactation record. However, if the resulting gestation length was $<220 \mathrm{~d}$ or $>300 \mathrm{~d}$, the conception dates were calculated as the next calving date minus $280 \mathrm{~d}$. When the record was not completed and a due date was reported, the conception date was calculated as $280 \mathrm{~d}$ before the provided due date. If a cow did not have a reported due date but was reported pregnant, then her last breeding date was used as the conception date. The due date was then estimated as $280 \mathrm{~d}$ after the conception date.

The culling date was the last known reported status date with the status code for culling. Records of cows culled with disposal codes other than the code of interest were also censored at the culling date. Cows culled with the disposal code dairy purposes were censored at the date of culling. However, events after 1,092 d since calving were ignored for censored cows and the last known event date was set to 1,092 d after the calving date. Therefore, the number of cow-days was calculated for each individual as the number of days between the calving date and culling or death date, the subsequent calving date, or the last known event date, whichever was earlier. Cow-days at risk for open cows were calculated as the number of days between calving and conception that resulted in a reported pregnancy or last known event date, whichever was earlier. Cow-days at risk for pregnant cows were calculated as the number of days between conception and calving or last known event date, whichever was earlier.

Herd parameters were estimated from the edited lactation records. Herd milk yield (305ME) and herd size per season and year were calculated. Annualized live culling and death rates were calculated as number of cows that were live culled or died divided by the number of cow-days at risk, times 365 (Fetrow et al., 2006).

\section{Events of Interest and Independent Variables}

The event of interest was culling with 1 of 9 disposal codes: feet and legs, low production, reproduction, injury/other, mastitis, disease, udder problems, died, and reason not reported. The disposal code dairy purposes was not considered. Independent variables included reproductive status, cow-relative 305ME milk yield, herd-relative 305ME milk yield, herd size, and year and season of culling. Time-to-event analyses for 
culling with various disposal codes in open versus pregnant cows were performed separately by parity $(1,2$, $3, \geq 4)$.

All variables were categorized. The distribution of the noncategorical variables was examined through the use of histograms and descriptive statistics to assist in their categorization. Independent variables were categorized as follows. Values for cow 305ME milk yield were provided in the DHI data set. Herd 305ME milk yield was estimated as the average of the individual values per herd year-season. Cow and herd 305ME milk yield and annualized herd live culling and death rates were expressed as relative values deviated from the mean and categorized as <mean - SD, mean - SD to mean $+\mathrm{SD}$, and >mean + SD. Cow-relative 305ME milk yield was calculated as the difference from the DHI reported herd mates' average milk yield: $<-2,313 \mathrm{~kg}$ (low), $-2,313$ to $2,187 \mathrm{~kg}$ (intermediate), and $>2,187 \mathrm{~kg}$ (high). Herd-relative 305ME milk yield was calculated as the difference from the herd year-season average: $<-243 \mathrm{~kg}$ (low), -243 to $243 \mathrm{~kg}$ (intermediate), and $>243 \mathrm{~kg}$ (high). Annualized herd live culling rate was categorized as $<17.6 \%$ (low), 17.6 to $32.5 \%$ (intermediate), and $>32.5 \%$ (high). Annualized herd death rate was categorized as $<2.8 \%$ (low), 2.8 to $10.5 \%$ (intermediate), and $>10.5 \%$ (high). Herd size was categorized as 100 to 200,201 to 500,501 to $1,500,1,501$ to 3,000 , and $>3,000$ cows. Seasons of culling were winter (January to March), spring (April to June), summer (July to September), and fall (October to December).

\section{Statistical Analysis}

The frequency of herds by number of disposal codes reported was estimated to determine whether all herds reported all 8 disposal codes (codes dairy purposes and reason not reported were excluded). The number and distribution of disposal codes used for each herd was also calculated (Figure 1). Annualized live culling and death rates were estimated by categories of explanatory variables. The distribution of disposal codes was analyzed by parity, days after calving, reproductive status, cow- and herd-relative 305ME milk yield, herd size, year, season, and geographic subpopulations (Northeast $=$ Pennsylvania, New York; Southeast $=$ Florida, Georgia) and for different levels of annualized herd live culling and death rates. These geographic subpopulations were chosen because a clear difference in seasonal effects was expected.

Hazard distributions for specific disposal codes were calculated by parity using the actuarial method of the LIFETEST procedure of SAS (release 9.2; SAS Institute Inc., Cary, NC). Records missing a subsequent calving date or a culling event and date were considered censored at the last known event date. The dynamics of risk for culling with various disposal codes for open and pregnant cows were analyzed separately. The analysis of open cows was considered from 1 to 500 $\mathrm{d}$ since calving and cows that became pregnant were censored at conception. In the analysis of pregnant cows, the conception date was considered as the origin time to account for differences in DIM at the moment of conception. Potential associations among disposal codes (including overall live culling) were hypothesized; correlations between culling rates with various disposal codes, expressed as absolute herd culling rates and as percentages relative to the total culling per herd, were calculated with the CORR procedure in SAS.

\section{RESULTS AND DISCUSSION}

\section{Distribution of Culling with Various Disposal Codes}

After edits, 3,629,002 observations in 2,054 herds were available for the analysis. Overall, $5.0 \%$ of the codes were reason not reported. Yet $0.3 \%$ of the culled cows had a missing disposal code despite the DHI policy to record reason not reported when the producer failed to provide a disposal code. The number of different disposal codes reported and number of herds reporting were as follows: 1 code reported ( 2 herds), 2 ( 7 herds), 3 (15 herds), 4 (25 herds), 5 (150 herds), 6 (149 herds), 7 (537 herds), and all 8 disposal codes reported $(1,168$ herds). Therefore, most the herds (57\%) reported all 8 different disposal codes of interest.

The relative frequency of cows culled with various disposal codes within the number of reported codes per dairy farm are presented in Figure 1. For example, 2 herds each reported just 1 disposal code. In herd A, cows left with reported disposal code injury/other $(53 \%$ of the cows that were culled in both herds); in herd B, cows left with reported disposal code died ( $47 \%$ of the cows that were culled in both herds). Comparing reported frequencies of disposal codes between dairy farms requires caution because of differences in case definitions and recording methods (Fetrow et al., 2006).

Overall, annualized live culling and death rates were 25.1 and $6.6 \%$, respectively (Table 1 ). Considering that this estimation does not include the disposal code dairy purposes, these values are within the reported ranges (Smith et al., 2000; Hadley et al., 2006). The primary reported disposal code was died (20.6\% of all culling), followed by reproduction (17.7\%), injury/other (14.3\%), and low production and mastitis (both 12.1\%). This is in partial agreement with data reported by Hadley et al. (2006), where injury/other was the primary reported reason for culling, followed by reproduction and 

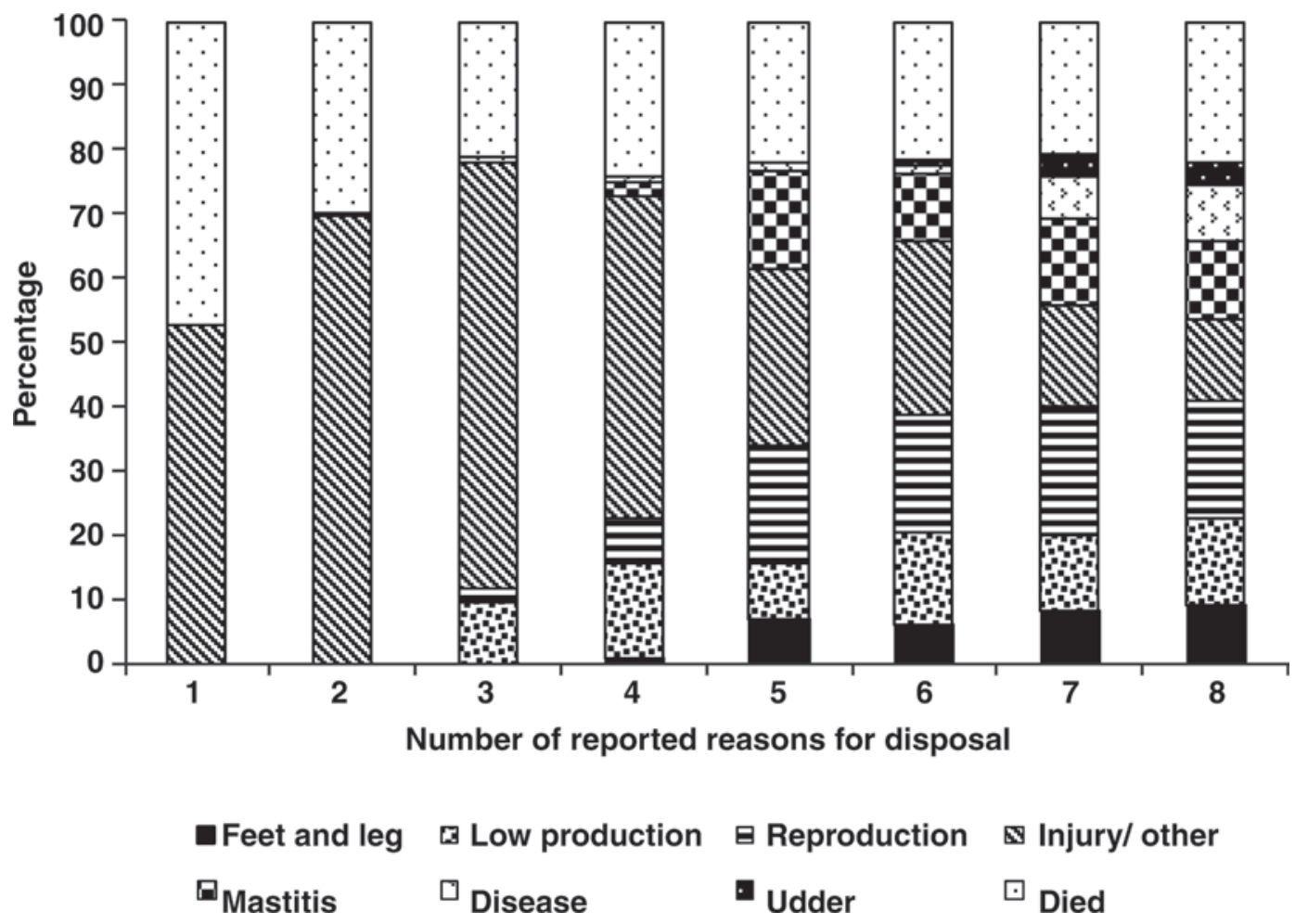

Figure 1. Frequency distribution of reported disposal codes by number of different reported codes by farm. Number of different disposal codes reported and number of herds reporting were as follows: 1 code reported ( 2 herds), 2 ( 7 herds), 3 (15 herds), 4 (25 herds), 5 (150 herds), 6 (149 herds), 7 (537 herds), and all 8 disposal codes reported (1,168 herds). For example, 2 herds reported each just 1 disposal code. In herd A, cows left with reported disposal code injury/other (53\% of the cows that were culled in both herds); in herd B, cows left with disposal code died ( $47 \%$ of the cows that were culled in both herds). The disposal codes dairy purposes and reason not reported are excluded.

low production. Two older studies conducted in New York are only in partial agreement with the present results indicating low production, reproduction, and udder problems as the primary reported reason for culling (Van Vleck and Norman, 1972; Milian-Suazo et al., 1988). Similarly, Bascom and Young (1998) reported reproduction as the primary reason for culling, followed by low production and mastitis. In England, reproduction was the most reported reason for culling (Esslemont and Kossaibati, 1997). Therefore, the risk of death appears to have increased over time.

The frequency distributions of culling risk with various disposal codes for different subgroups are reported in Table 1. Increasing values for annualized live culling rates were associated with decreasing categories of annualized death rates, which is in agreement with data reported by McConnel et al. (2008).

The most often reported disposal code in parity 1 and 2 was reproduction (20.4 and $20.7 \%$ of all culling, respectively). For cows in parity 3 and $\geq 4$, died was the most frequently reported code (21.4 and $22.3 \%$, respectively). As previously reported (van Arendonk and Dijkhuizen, 1985; Thomsen et al., 2004; Miller et al.,
2008 ), cows in a higher parity were at a greater risk ( $P$ $<0.001$ ) for overall live culling (annualized live culling rates from $16.9 \%$ for parity 1 to $40.8 \%$ for parity $\geq 4$ ) and for death (annualized death rates from $3.9 \%$ for parity 1 to $11.7 \%$ for parity $\geq 4$ ).

For pregnant cows, died was the main reported disposal code ( $19 \%$ of all culling), followed by reproduction $(18.9 \%)$. In open cows, died $(28.2 \%)$ was followed by injury/other (12.7\%). Pregnant cows had a lower annualized live culling rate $(7.2 \%)$ compared with open cows (40.4\%). Similarly, the annualized death rate was lower for pregnant cows (3.1\%) than for open cows (11.1\%). Dairy producers may provide preferential treatment to pregnant cows when they get sick. Furthermore, healthier cows may get pregnant sooner.

In pregnant cows, reproduction was the second most often reported disposal code. Pregnancy loss rates close to $20 \%$ have been reported (Pursley et al., 1998); therefore, cows may first have been diagnosed pregnant but found to be open later without this finding being reported.

In low-producing cows, low production was the most frequently reported disposal code $(21.0 \%$ of total cull- 
ing). The annualized live culling rate in this group was high $(72.8 \%)$, which indicates that low milk production is a major driver of culling.

For intermediate- and high-producing cows, reproduction was the most often reported disposal code (25.5 and $29.7 \%$, respectively). Annualized live culling and death rates decreased with greater cow-relative $305 \mathrm{ME}$ milk yield. These results are in agreement with those reported by Hadley et al. (2006), where cows producing $45 \mathrm{~kg}$ more milk than average 305ME milk yield were 0.5 to $1.7 \%$ less likely to be culled than the averageproducing cow. Regardless of an adverse genetic relationship between yield traits and survival, phenotypic correlations between survival and yields suggested that preferential treatment by the dairy producer for high-yielding cows made their survival rates higher than those for low-producing cows (Dematawewa and Berger, 1998).

Reproduction was the most frequently reported disposal code for the 3 categories of herd-relative $305 \mathrm{ME}$ milk yield. In agreement with previous data (Smith et al., 2000), greater herd-relative 305ME milk yield was associated with greater annualized live culling rates. However, contrary to some reports (McConnel et al., 2008; Miller et al., 2008), there was not an association between greater herd-relative 305ME milk yield and

Table 1. Annualized live culling rate and death rate and frequency distribution of culling with various DHI reported disposal codes (as a \% of total culling risk) for different subgroups

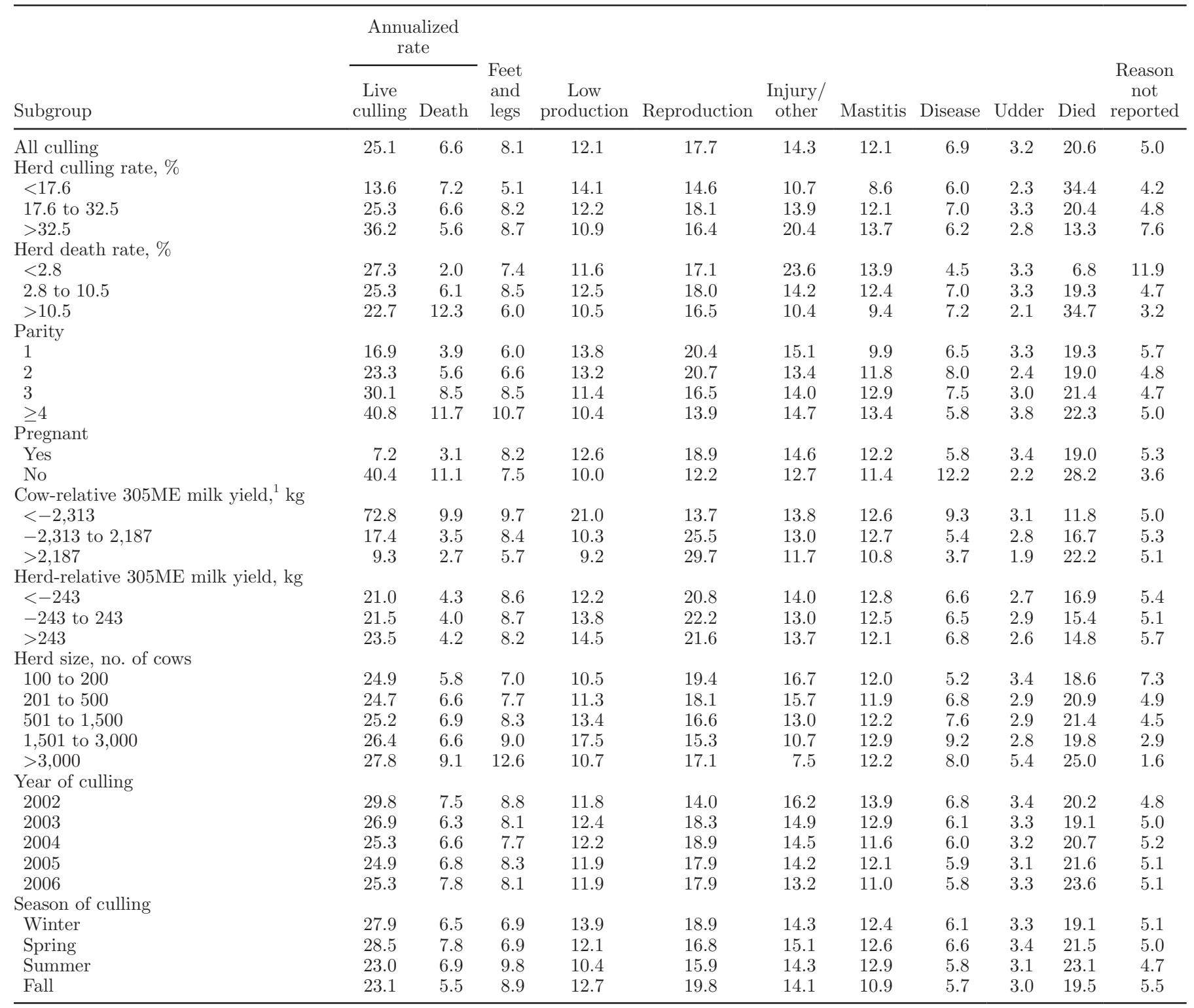

${ }^{1} 305 \mathrm{ME}=305$-d mature equivalent. 


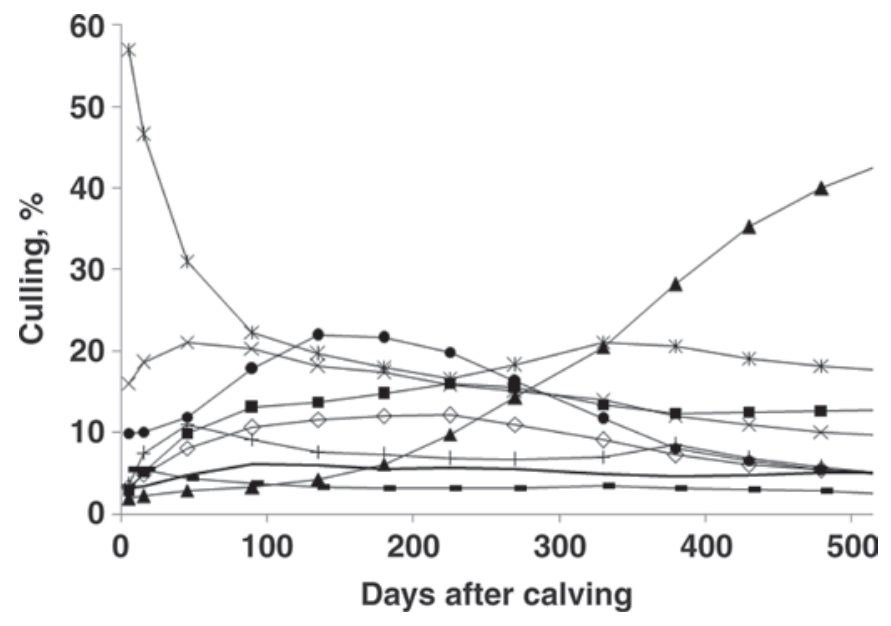

Figure 2. Distribution of culled cows (\%) by disposal codes at different stages of lactation (each day is $100 \%$ ). Disposal codes: feet and legs $(\diamond)$, low production $(\boldsymbol{\square})$, reproduction $(\boldsymbol{\Delta})$, injury/other $(\times)$, died $(*)$, mastitis $(\bullet)$, disease $(+)$, udder problems $(\mathbf{-})$, and reason not reported (clean line).

increased death rates. In other studies (van Arendonk and Dijkhuizen, 1985; Scott, 1994), herd production level did not affect culling rate or was slightly negatively correlated with involuntary culling (Rogers et al., 1988; Smith et al., 2000).

Excluding herds with $<200$ cows, died was the most frequently reported disposal code in all herd size categories. In this study, larger herds had greater live culling and death rates. A trend to lower annualized culling rates was found for more recent culling. The largest annualized live culling and death rates were reported for cows leaving the herd during spring. Previous studies reported a positive association between herd size and the risk of death (Smith et al., 2000; McConnel et al., 2008).

The distribution of risk of culling with various disposal codes by days after calving is presented in Figure 2 . The relative frequencies varied with stage of lactation, with the disposal codes died and reproduction showing the most remarkable change. During the first $100 \mathrm{~d}$ after calving, died was the most often reported disposal code. The proportion cows with disposal code died of all cows culled decreased from 57 to $22 \%$ in that period and decreased to about $20 \%$ by $120 \mathrm{~d}$. This high occurrence of death in early lactation is in agreement with previous studies (Hadley et al., 2006; Dechow and Goodling, 2008), where died was the most common culling reason by $60 \mathrm{~d}$ after calving (42 and $44.6 \%$, respectively). Conversely, reproduction was the most often reported disposal code after $350 \mathrm{~d}$ after calving. The proportion of cows culled with disposal code reproduction increased from $5 \%$ during the first $150 \mathrm{~d}$ to $40 \%$ of all culling by $500 \mathrm{~d}$ after calving.
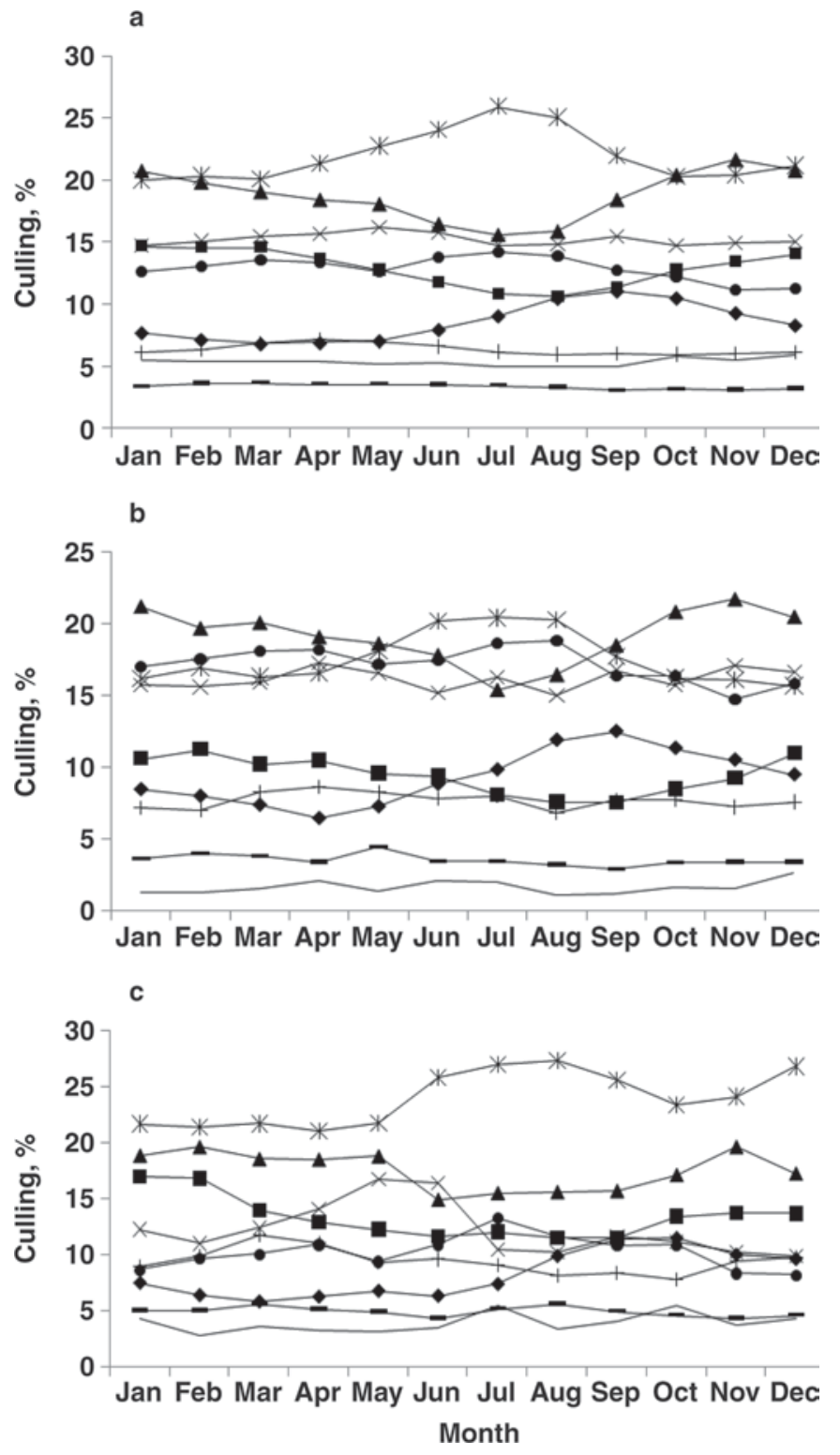

Figure 3. Distribution of culled cows (\%) by disposal codes by month of culling and geographic area $[\mathrm{a}=$ overall; $\mathrm{b}=$ Northeast (Pennsylvania, New York); c = Southeast (Florida, Georgia)]; each month is $100 \%$. Disposal codes: feet and legs $(\diamond)$, low production $(\boldsymbol{\square})$, reproduction $(\mathbf{\Lambda})$, injury/other $(\times)$, died $(*)$, mastitis $(\bullet)$, disease $(+)$, udder problems $(\mathbf{-})$, and reason not reported (clean line).

Changes occurring in the distribution of culling risk by month and geographic area are provided in Figure 3. A seasonal pattern is noticed for culling with disposal code died in the overall population as well as in the 2 geographic subpopulations, with an increase in its relative importance during the summer months. This was the most often reported disposal code during all seasons in the Southeast. Summer was also the season with the greatest risk for death in Italy (Vitali et al., 2009). In the 3 populations, an increase in culling with 

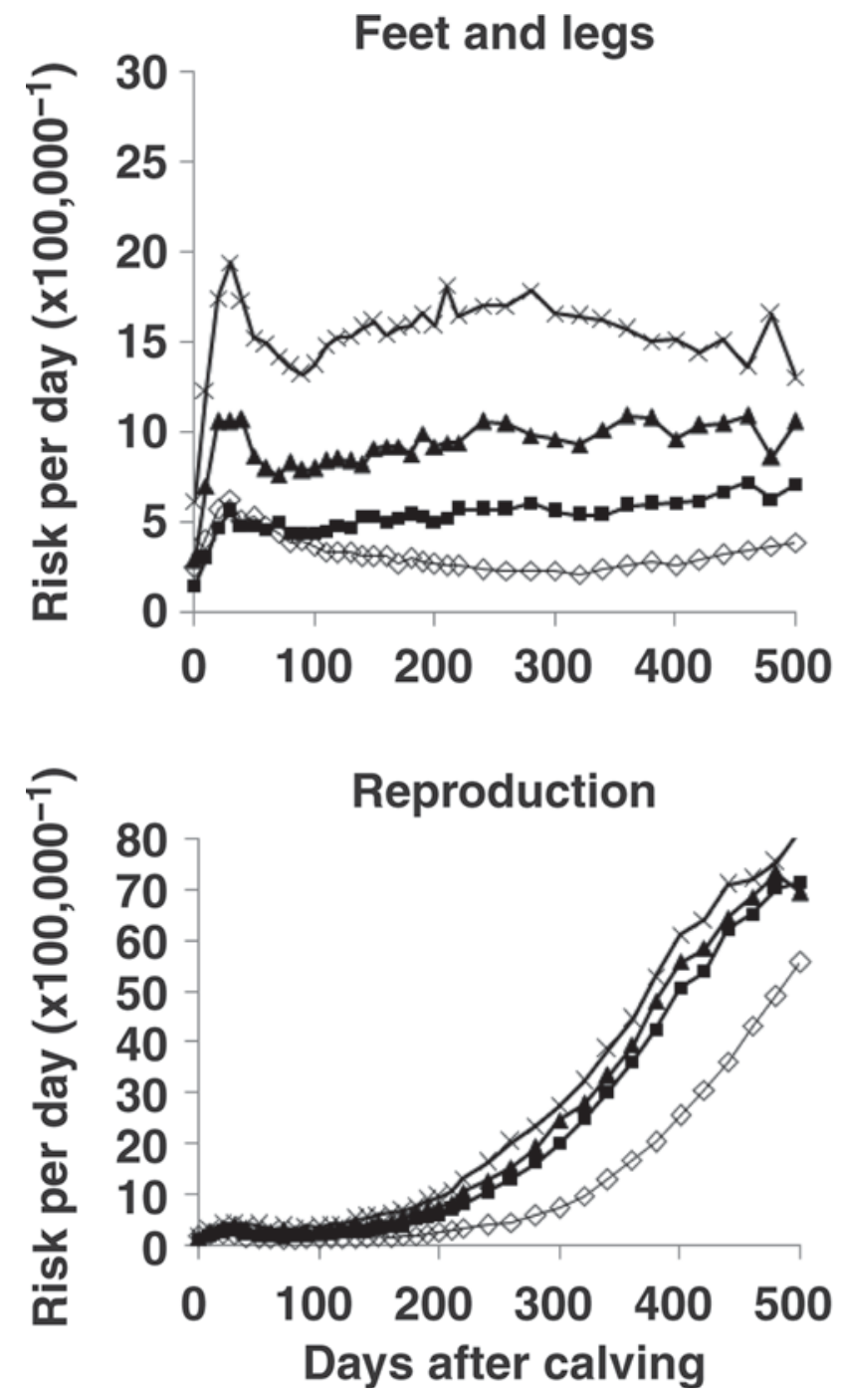
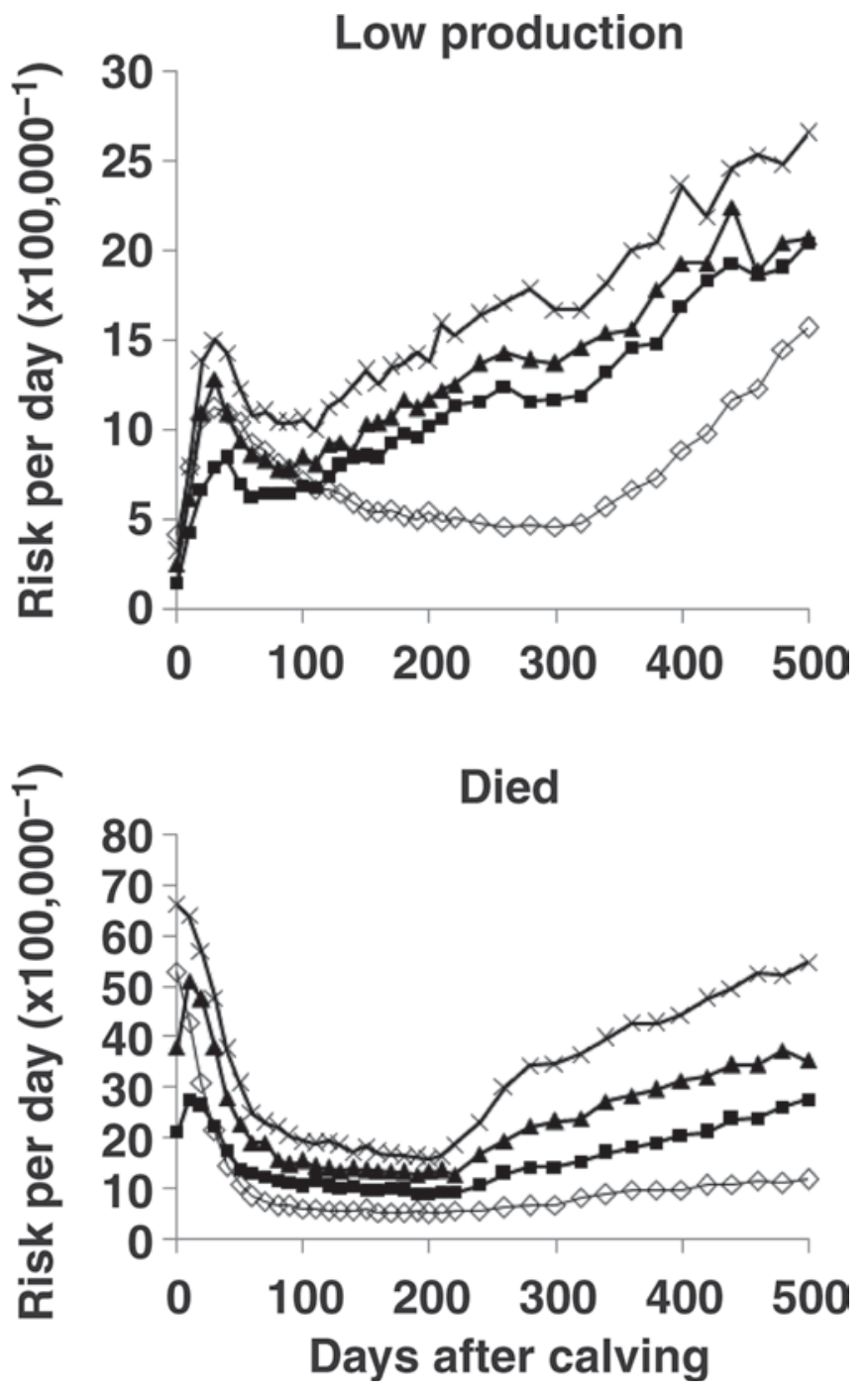

Figure 4. Risk of culling $\left(\times 100,000^{-1}\right)$ in open cows by days after calving and parity with disposal codes feet and legs, low production, reproduction, and died (scales vary for y-axis). Parity $1(\diamond)$; parity $2(\mathbf{\square})$; parity $3(\boldsymbol{\Delta})$; parity $\geq 4(\times)$.

disposal code reproduction after the summer may be a consequence of failure to get cows pregnant during the hot season. As reported by Smith et al. (2000) for the southern region, reproduction was reported more in the Southeast compared with the Northeast, maybe as a result of the effect of high levels of heat and humidity. The disposal codes mastitis and injury/other were more often reported across the year in the Northeast compared with the Southeast.

\section{Correlation Analysis}

Correlations among relative culling rates (\% of total culling per herd) and among absolute herd culling rates for culling with various disposal codes are presented in Table 2 . The correlation between overall live culling rate and culling rates with various disposal codes was positive with the exception of the disposal code died. The correlation between herd live culling rate and culling with disposal code died was negative for both absolute and relative values $(\mathrm{r}=-0.16$ and -0.22 , respectively), suggesting that herds that delayed culling decisions had increased numbers of deaths. This finding agrees with previous data (McConnel et al., 2008), where herds with a low percentage of cows that were culled in early lactation had greater levels of mortality. Note that the factors associated with higher live culling rates (parity, pregnancy status, cow-relative 305ME milk yield, herd size, season of culling) are also associated with high death rates (Table 1 ).

For the absolute rates in Table 2, the greatest positive correlation among culling risks with various dis- 

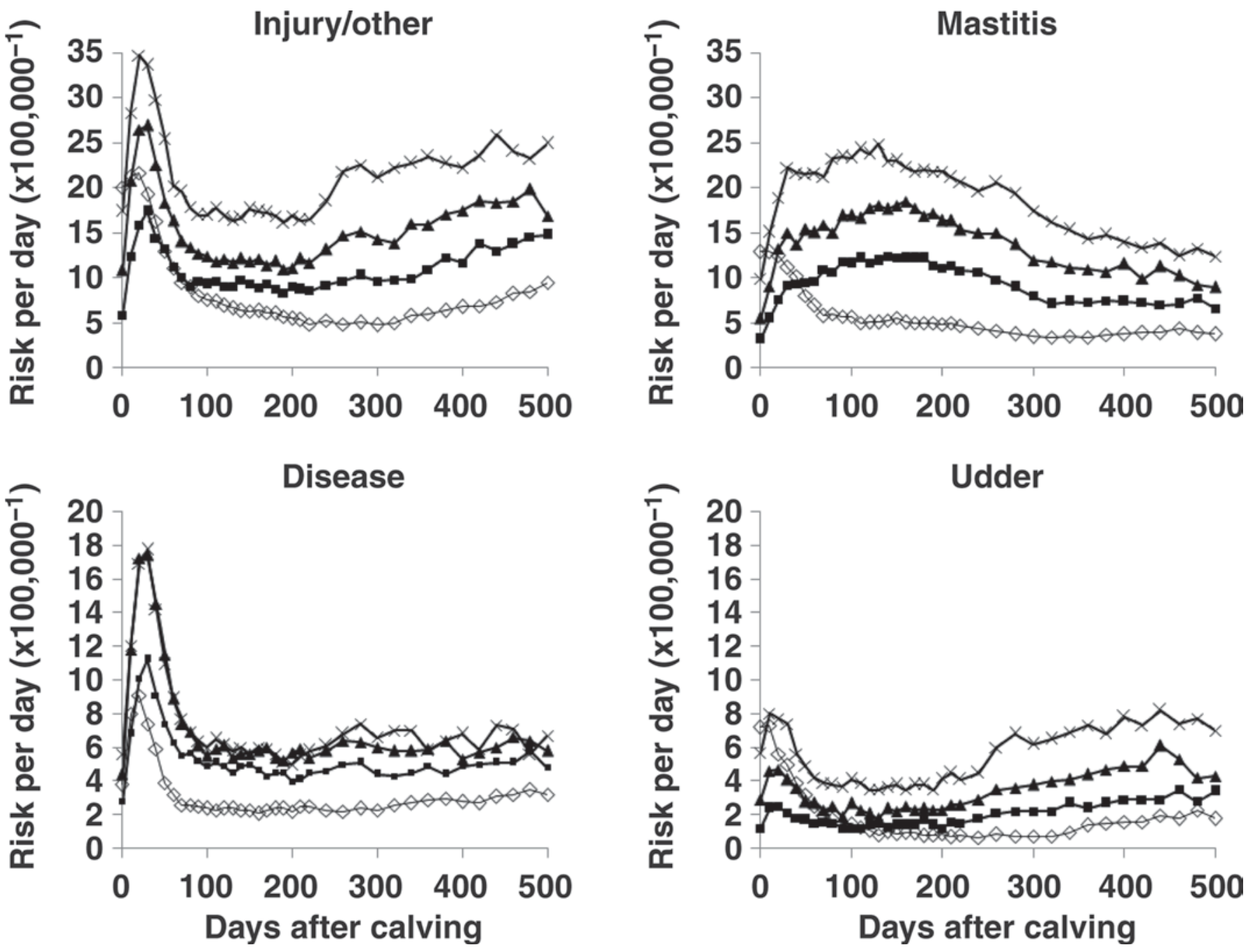

Figure 5. Risk of culling $\left(\times 100,000^{-1}\right)$ in open cows by days after calving and parity with disposal codes injury/other, mastitis, disease, and udder (scales vary for y-axis). Parity $1(\diamond)$; parity $2(\mathbf{\square})$; parity $3(\boldsymbol{\Lambda})$; parity $\geq 4(\times)$.

Table 2. Pearson correlation coefficients for pairs of herd culling risk by DHI reported disposal code ${ }^{1}$

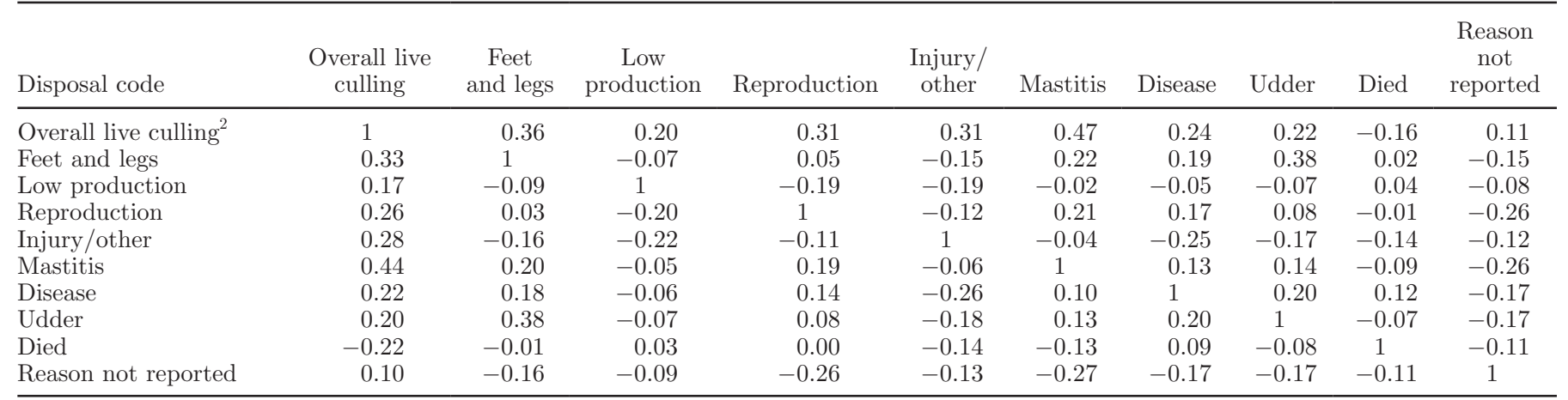

${ }^{1}$ Actual culling risks above the diagonal and relative culling risks (total culling risk is 100\%) per herd below the diagonal.

${ }^{2}$ All disposal codes except disposal code died. 
posal codes was for the pairs feet and leg and udder, followed by feet and leg and mastitis. The positive association between culling for feet and leg and udder may indicate that some herds are culling cows based on poor conformation of these traits instead of observed health problems. Excluding reason not reported, the strongest negative correlation was for injury/other and disease, followed by injury/other and low production together with low production and reproduction. As expected, the correlation between culling with disposal code reason not reported and all other disposal codes was negative.

These correlations suggest that many cows are likely being culled for multiple reasons. For example, the disposal codes low production and reproduction are expected to be similar reasons for cows late in lactation that failed to get pregnant. Dairy producers will likely have a preference for reporting the same DHI disposal code.

\section{Hazard Functions for Culling with Various Disposal Codes}

When the risk for culling with various disposal codes was quantified by pregnancy status, open cows had a 2 to 4 times greater risk for culling compared with pregnant cows (Figures 4, 5, 6, and 7). As for highproducing cows, this finding may imply a preferential treatment that increased their chances for survival. It is also likely that healthier cows were more likely to be pregnant.

Given that cows are usually not inseminated before $50 \mathrm{~d}$ after calving, Figures 4 and 5 for open cows included all the cows up to this time after calving. Cows that became pregnant were censored at conception. Generally, pregnancy is diagnosed after $28 \mathrm{~d}$ or later post-breeding. Consequently, as shown in Figures 6 and 7 , the analysis estimated the risk of live culling and death for pregnant cows during this time to be near 0 . Cows culled shortly after conception were reported to be open.

For open cows in all parities, the risk of culling with disposal code feet and legs peaked around $20 \mathrm{~d}$ after calving and remained stable until next calving. In pregnant cows, the risk peaked around $150 \mathrm{~d}$ of gestation that was more manifest for parities 3 and $\geq 4$, but not evident for parity 1 (Figures 4 and 6). As shown in Table 1, the relative frequency of culling with disposal code feet and leg was similar between pregnant and open cows (8.2 and $7.5 \%$, respectively). However, the absolute risk for culling with disposal codes feet and legs was about double for open cows compared with pregnant cows.
For open cows, the risk for culling with disposal code low production increased transitorily around $15 \mathrm{~d}$ after calving to steadily increase with days after calving. This increase showed a time lag in the case of cows in parity 1 . A different pattern was found in pregnant cows where the risk increased up to $120 \mathrm{~d}$ of pregnancy and then decreased (Figures 4 and 6). This level of culling with disposal code low production was not expected for pregnant cows and it likely included cows that were initially diagnosed pregnant and were found open later, but this change of status was not reported. Therefore, at least a proportion of this group was likely not pregnant and, consequently, it is expected that the inclusion of these cases overestimated the culling risk in pregnant cows.

For open cows, the risk of culling with disposal code reproduction steadily increased after $200 \mathrm{~d}$ post-calving (Figures 4 and 6). For pregnant cows, the risk remained low until $100 \mathrm{~d}$ after conception and slightly increased with days pregnant. The relative frequency of reported culling with disposal code reproduction was the highest in pregnant cows (18.9 vs. $12.2 \%$ in open cows). Similarly to the risk of culling with disposal code low production, this risk may be overestimated given that the calculation likely included some cows that were open but were reported to be pregnant.

For open cows, the highest risk of culling with disposal code died was right after calving and decreased until $150 \mathrm{~d}$ and increased again after $200 \mathrm{~d}$ post-calving. In pregnant cows, the risk increased steadily from $\mathrm{d} 50$ of pregnancy (Figures 4 and 6). The relative frequency of death was about 3 times as low in pregnant cows compared with open cows.

The risk of culling with disposal code injury/other peaked around $20 \mathrm{~d}$ after calving for open cows and remained stable afterward. In pregnant cows, the risk increased up to $100 \mathrm{~d}$ of pregnancy and remained stable afterward (Figures 5 and 7). The relative frequency of culling with disposal code injury/other was similar for the 2 groups.

For open cows in parity 2 or higher, the highest risk of culling with disposal code mastitis was in the period $20 \mathrm{~d}$ to $250 \mathrm{~d}$ after calving. Conversely, first-parity cows had the highest risk right after calving. In pregnant cows, the highest risk was in the period 70 to $160 \mathrm{~d}$ after conception (Figures 5 and 7 ).

For open cows, the risk of culling with disposal code disease markedly increased around $30 \mathrm{~d}$ after calving, then decreased and remained constant after around 100 $d$ until the end of the lactation. In pregnant cows, the risk increased up to $100 \mathrm{~d}$ of pregnancy and remained stable afterward (Figures 5 and 7 ). The relative frequency of culling with disposal code disease was about 

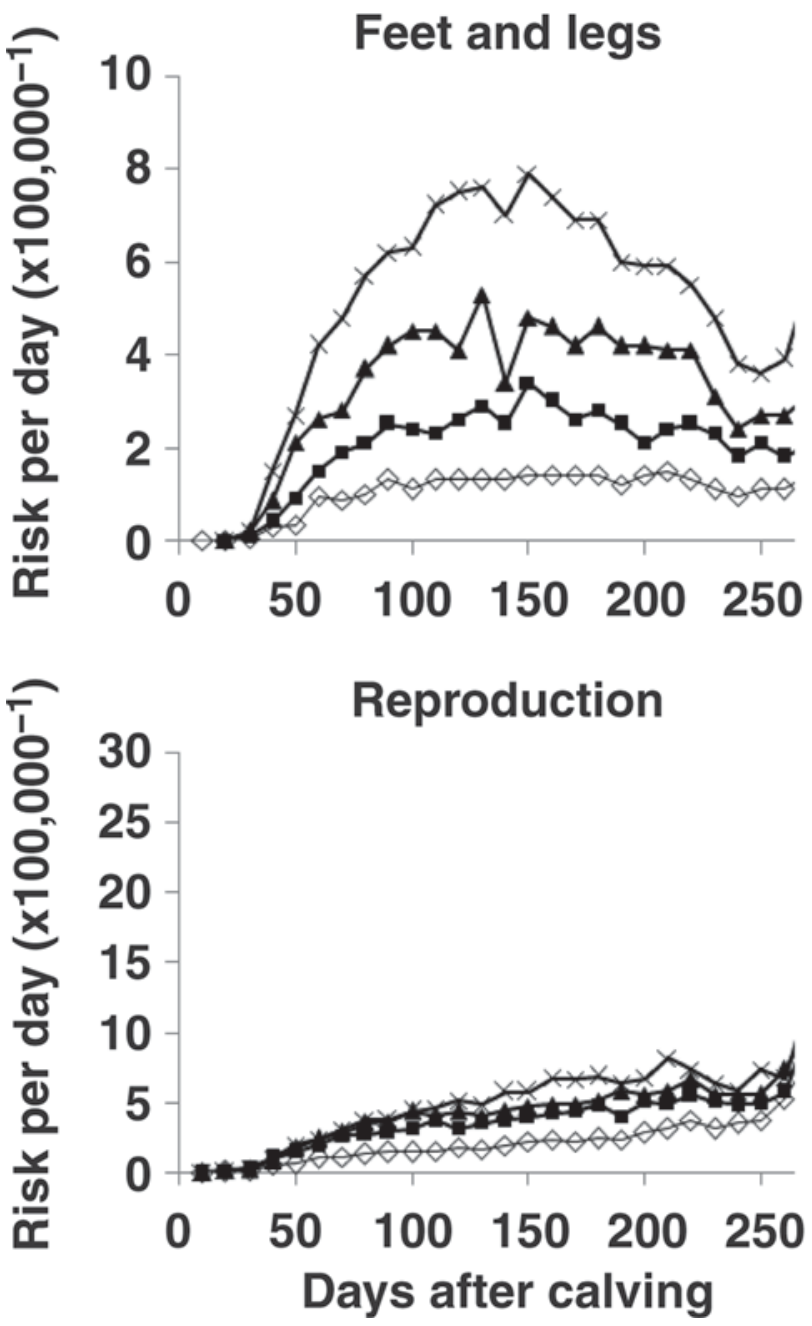
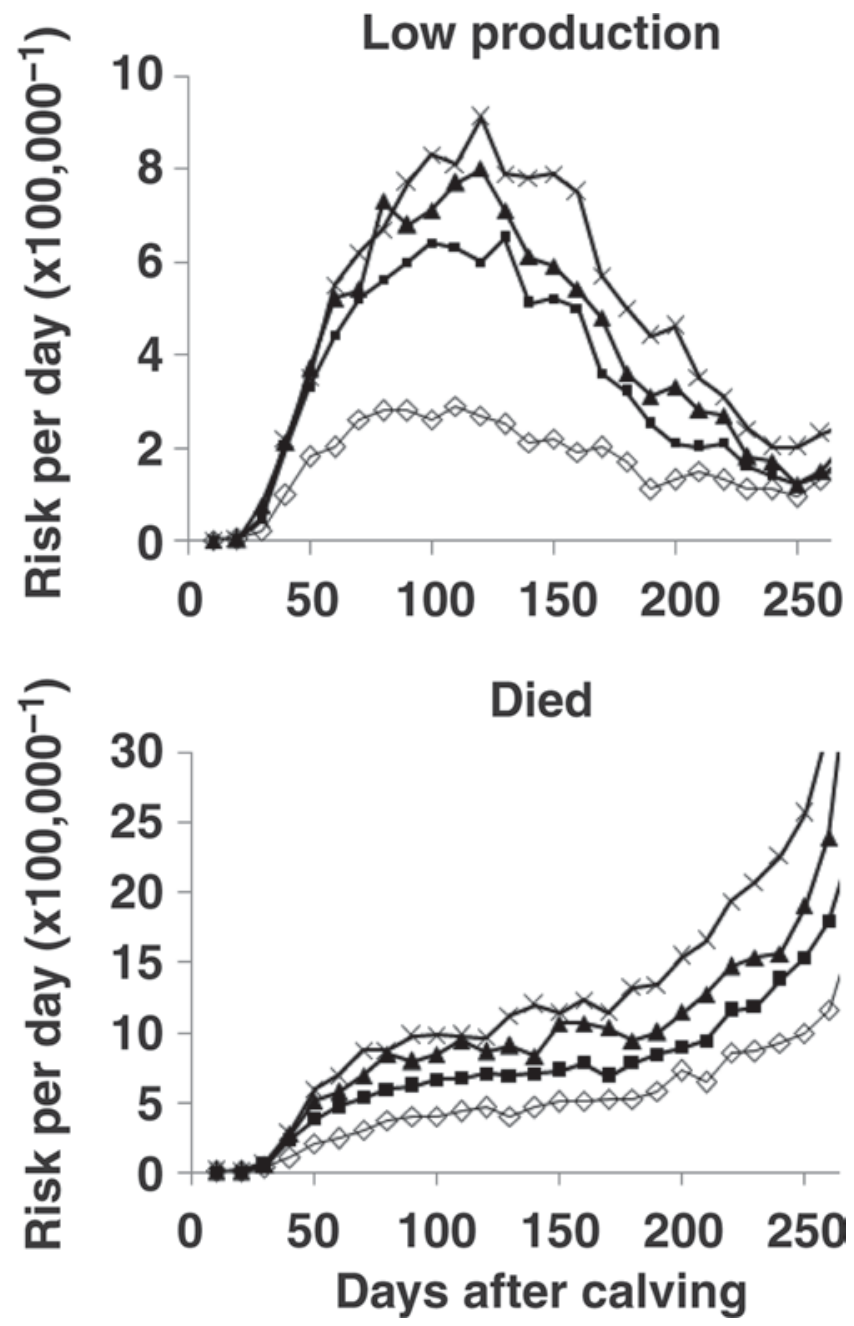

Figure 6. Risk of culling $\left(\times 100,000^{-1}\right)$ in pregnant cows by days after calving and parity with disposal codes feet and legs, low production, reproduction, and died (scales vary for y-axis). Parity $1(\diamond)$; parity $2(\boldsymbol{\square})$; parity $3(\mathbf{\Lambda})$; parity $\geq 4(\times)$.

2 times greater in open cows compared with pregnant cows (12.2 vs. $5.8 \%$, respectively).

For open cows, the risk of culling with disposal code udder increased transitorily around $15 \mathrm{~d}$ after calving. The risk started to increase again around d 250 until next calving. In pregnant cows in parity 3 and $\geq 4$, the risk increased up to $200 \mathrm{~d}$ of pregnancy. Cows in parities 1 and 2 had a more stable pattern after $80 \mathrm{~d}$ of gestation (Figures 5 and 7).

\section{CONCLUSIONS}

This study described risk factors for culling with dairy producers' reported primary disposal codes. Because most cows leave the herd for a combination of reasons (Van Vleck and Norman, 1972; Fetrow et al., 2006), the reported disposal code should not be interpreted as being the single reason of disposal from the herd.
Also, $43 \%$ of herds were found to not report all disposal codes. The dynamics of culling risk with various disposal codes were dependent on stage of lactation, parity, milk yield, reproductive status, and herd characteristics. Early lactation was a critical period for culling with disposal codes died, injury/other, and disease. The risk increased with days after calving for culling with disposal codes low production and reproduction. A negative association between overall live culling and death was found. Pregnancy and high relative $305 \mathrm{ME}$ milk yield were associated with a lower risk for culling with all disposal codes.

\section{ACKNOWLEDGMENTS}

The authors thank Pfizer Animal Health (Fort Collins, CO) for financial support that partly funded this study. Dairy Records Management Systems (Raleigh, 

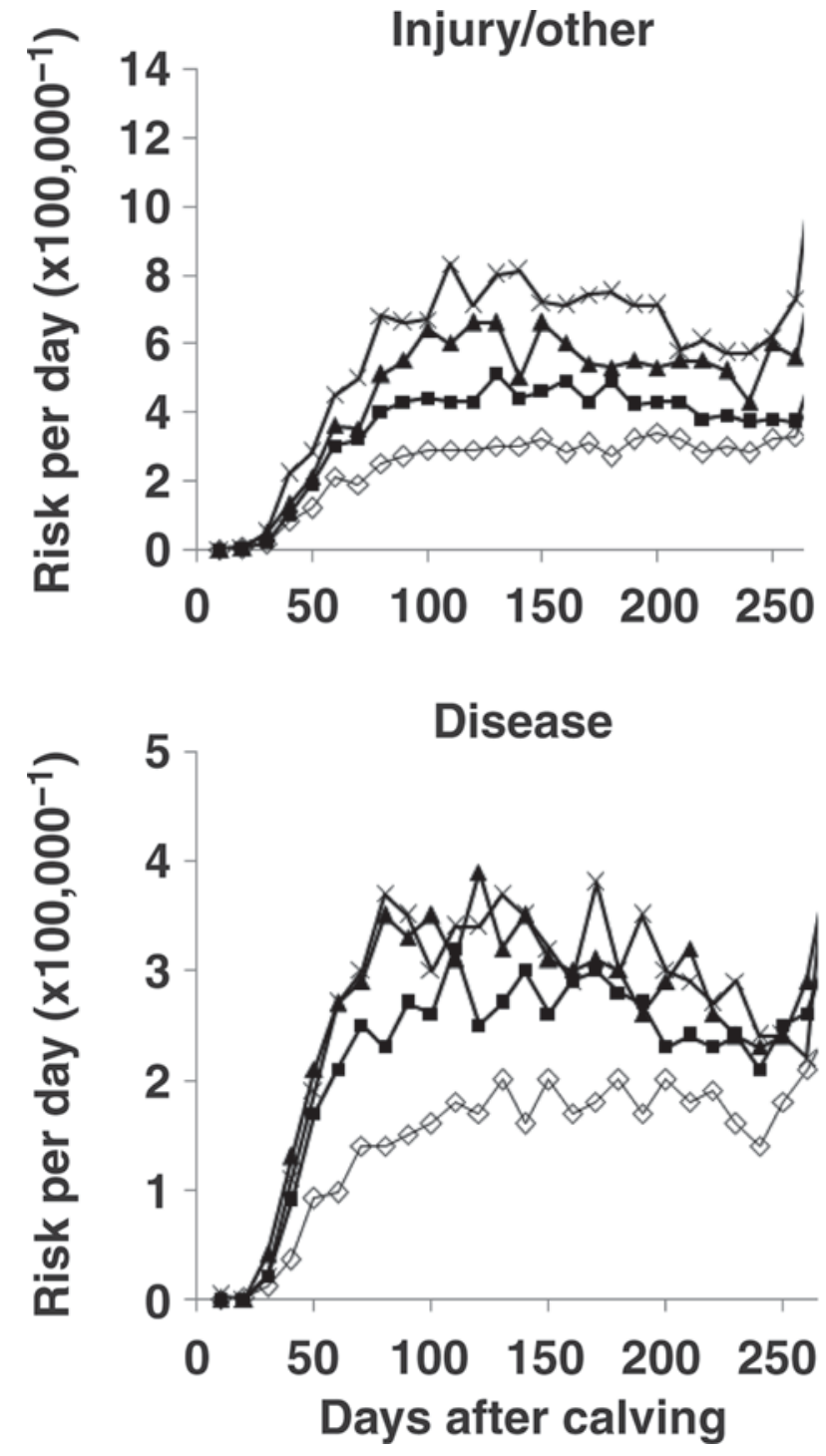

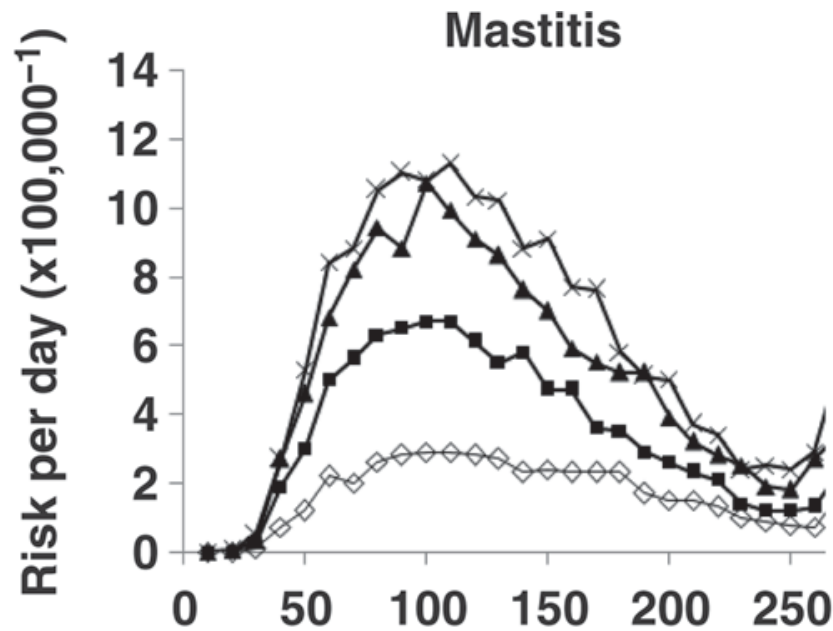

Udder

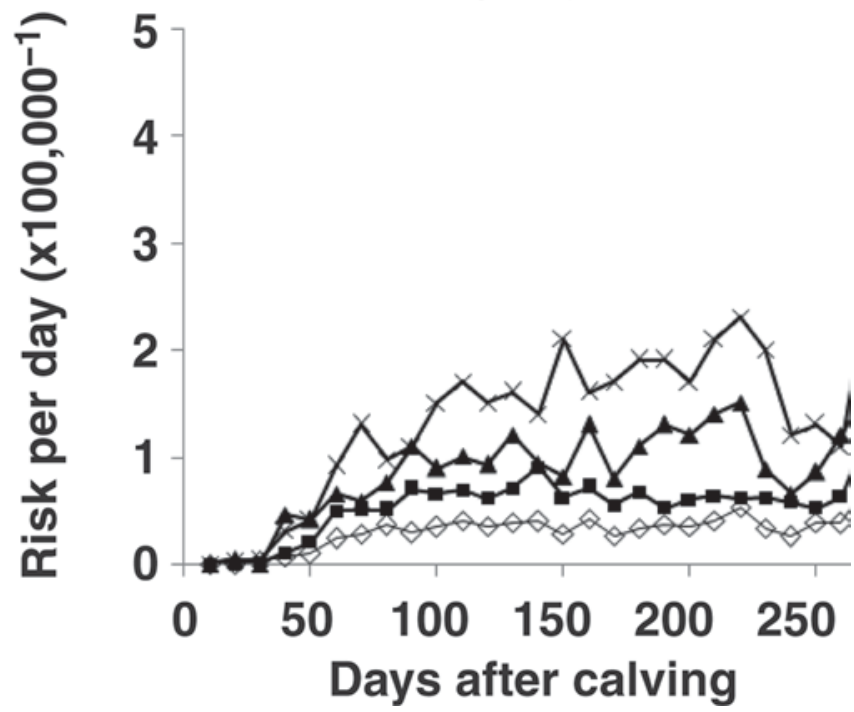

Figure 7. Risk of culling $\left(\times 100,000^{-1}\right)$ in pregnant cows by days after calving and parity with disposal codes injury/other, mastitis, disease, and udder (scales vary for y-axis). Parity $1(\diamond)$; parity $2(\boldsymbol{\square})$; parity $3(\boldsymbol{\Lambda})$; parity $\geq 4(\times)$.

$\mathrm{NC}$ ) is acknowledged for supplying the data in this study.

\section{REFERENCES}

Bascom, S. S., and A. J. Young. 1998. A summary of the reasons why farmers cull cows. J. Dairy Sci. 81:2299-2305.

Dechow, C. D., and R. C. Goodling. 2008. Mortality, culling by sixty days in milk, and production profiles in high- and low-survival Pennsylvania herds. J. Dairy Sci. 91:4630-4639.

Dematawewa, C. M., and P. J. Berger. 1998. Genetic and phenotypic parameters for 305-day yield, fertility, and survival in Holsteins. J. Dairy Sci. 81:2700-2709.

DRMS. 2004. DHI Glossary. Dairy Records Management Systems, Raleigh, NC.

Esslemont, R. J., and M. A. Kossaibati. 1997. Culling in 50 dairy herds in England. Vet. Rec. 140:36-39.
Fetrow, J., K. V. Nordlund, and H. D. Norman. 2006. Invited review: Culling: Nomenclature, definitions, and recommendations. J. Dairy Sci. 89:1896-1905.

Goff, J. P., and R. L. Horst. 1997. Physiological changes at parturition and their relationship to metabolic disorders. J. Dairy Sci. 80:1260-1268.

Hadley, G. L., C. A. Wolf, and S. B. Harsh. 2006. Dairy cattle culling patterns, explanations, and implications. J. Dairy Sci. 89:22862296.

Hare, E., H. D. Norman, and J. R. Wright. 2006. Survival rates and productive herd life of dairy cattle in the United States. J. Dairy Sci. 89:3713-3720.

McConnel, C. S., J. E. Lombard, B. A. Wagner, and F. B. Garry. 2008. Evaluation of factors associated with increased dairy cow mortality on United States dairy operations. J. Dairy Sci. 91:1423-1432.

Milian-Suazo, F., H. N. Erb, and R. D. Smith. 1988. Descriptive epidemiology of culling in dairy cows from 34 herds in New York State. Prev. Vet. Med. 6:243-251. 
Milian-Suazo, F., H. N. Erb, and R. D. Smith. 1989. Risk factors for reason-specific culling of dairy cows. Prev. Vet. Med. 7:19-29.

Miller, R. H., M. T. Kuhn, H. D. Norman, and J. R. Wright. 2008. Death losses for lactating cows in herds enrolled in dairy herd improvement test plans. J. Dairy Sci. 91:3710-3715.

Pursley, J. R., R. W. Silcox, and M. C. Wiltbank. 1998. Effect of time of artificial insemination on pregnancy rates, calving rates, pregnancy loss, and gender ratio after synchronization of ovulation in lactating dairy cows. J. Dairy Sci. 181:2139-2144.

Rajala-Schultz, P. J., and Y. T. Gröhn. 1999. Culling of dairy cows. Part III. Effect of diseases, pregnancy status and milk yield on culling in Finnish Ayrshire cows. Prev. Vet. Med. 41:295-309.

Rogers, G., J. van Arendonk, and B. McDaniel. 1988. Influence of production and prices on optimal culling rates and annualized net revenue. J. Dairy Sci. 71:3453-3462.

Schneider, M. del P., E. Strandberg, U. Emanuelson, K. Grandhinson, and A. Roth. 2007. The effect of veterinary-treated clinical mastitis and pregnancy status on culling in Swedish dairy cows. Prev. Vet. Med. 80:179-192.

Scott, A. 1994. The economic advantage of longevity in the dairy cow. J. Agric. Econ. 45:113-122.

Sewalem, A., F. Miglior, G. J. Kistemaker, P. Sullivan, and B. J. van Doormaal. 2008. Relationship between reproduction traits and functional longevity in Canadian dairy cattle. J. Dairy Sci. 91:1660-1668.

Smith, J. W., L. O. Ely, and A. M. Chapa. 2000. Effect of region, herd size, and milk production on reasons cows leave the herd. J. Dairy Sci. 83:2980-2987.

Thomsen, P. T., A. M. Kjeldsen, J. T. Sørensen, and H. Houe. 2004. Mortality (including euthanasia) among Danish dairy cows (19902001). Prev. Vet. Med. 62:19-33.

van Arendonk, J. A. M., and A. A. Dijkhuizen. 1985. Studies on the replacement policies in dairy cattle. III. Influence of variation in reproduction and production. Livest. Prod. Sci. 13:333-349.

Van Vleck, L. D., and H. D. Norman. 1972. Association of type traits with reasons for disposal. J. Dairy Sci. 55:1698-1705.

Vitali, A., M. Segnalini, L. Bertocchi, U. Bernabucci, A. Nardone, and N. Lacetera. 2009. Seasonal pattern of mortality and relationships between mortality and temperature-humidity index in dairy cows. J. Dairy Sci. 92:3781-3790.

Weigel, K. A., R. W. Palmer, and D. Z. Caraviello. 2003. Investigation of factors affecting voluntary and involuntary culling in expanding dairy herds in Wisconsin using survival analysis. J. Dairy Sci. 86:1482-1486. 